\title{
Towards a paradigm shift in cancer screening: informed citizens instead of greater participation
}

\author{
Germany aims to stop nudging the public on screening
}

\author{
Gerd Gigerenzer director, Harding Centre for Risk Literacy and Centre for Adaptive Behaviour and \\ Cognition, Max Planck Institute for Human Development, Berlin, Germany
}

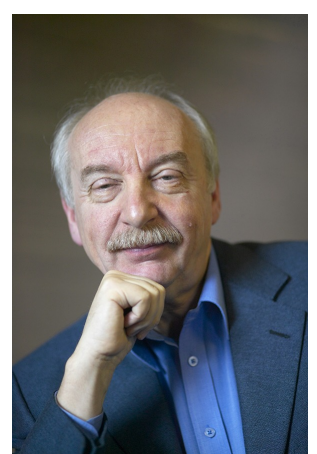

Policy on screening people for cancer poses a dilemma: should we aim for higher participation rates or for better informed citizens? The dilemma is that both cannot be had. A focus on informing citizens risks lowering participation rates, because well informed people may realise that for most cancers it is unclear whether the benefits of screening exceed its harms. Historically, screening policies opted for increasing participation and accordingly took measures that made people overestimate the benefits and underestimate the harms. ${ }^{1}$ But that is set to change, at least in Germany.

The goal of increasing participation rates has been moderately successful. For instance, German breast cancer screening campaigns set a goal of participation of $70 \%$ of eligible women and reached over 50\%. Similarly, the NHS Breast Screening Programme in England aimed for an $80 \%$ participation rate and reached over $70 \%{ }^{2}$ But campaigns for this screening test and most other cancer screening tests have caused people in rich countries to widely overestimate benefits and underestimate harms. ${ }^{3}$ Only 2-4\% of German and British women understand the benefit of breast cancer screening, while the rest overestimate it 10-fold, 100-fold, or 200-fold or do not know. ${ }^{4}$ By comparison, in Russia, where pink ribbon campaigns do not exist and the participation rate is relatively low, $18 \%$ of women understand the benefits.

\section{Turning the tables in screening}

But Germany's National Cancer Plan, which was initiated by the government in 2008 and coordinates screening and treatment, is now turning the tables. It was announced at a workshop in February 2015 that, on the basis of a 2013 law on improving the detection of cancer," "the goal of informed participatory decision making is now ranked higher than the goal of a maximum participation rate in cancer screening." ${ }^{\prime \prime}$ To change policy so clearly and publicly is unprecedented and represents a potential paradigm shift in screening. Its implementation will require fundamental changes. In my view, these include the following.

\section{Evidence based information}

All screening pamphlets and websites aimed at the public need to abandon persuasion and provide evidence based and transparent information. "Evidence based" means that both the pros and the cons of screening should be reported, such as those discussed in Cochrane reviews. "Transparent" means that the magnitude of the pros and cons is reported, instead of merely unquantified assertions, and that these numbers are reported as transparent absolute risks instead of misleading statistics such as relative risks and five year survival rates. ${ }^{7}$ One efficient instrument would be fact boxes for all kinds of screening. ${ }^{8}$

\section{Training for health professionals}

All health professionals need efficient training in health statistics and in communicating risk to patients. Studies indicate that most doctors do not understand the benefits of cancer screening and fall prey to misleading statistics. ${ }^{9}$ To change this situation requires:

- Revising university curriculums so that every medical student learns about health statistics and how to evaluate medical research articles, as well as how to communicate this evidence in a way that patients can understand. Adequate coverage of these three skills would require some 100 hours of curriculum time, including practical training, 
- Ensuring that continuing medical education includes training in risk literacy and communication. Medical organisations responsible for continuing medical education should consider ending their reliance on industry funding to sponsor educational programmes.

\section{Increasing public health literacy}

Not just patients with cancer and people at risk of cancer but also the general public needs good health education. The most effective way would be to start early in school and to provide enjoyable teaching activities to children and adolescents to improve their basic knowledge of health and so that they learn health associated skills such as cooking.

\section{The right to knowledge}

Germany has made some progress on the first goal, improving the information provided to patients. Misleading statistics, once the staple of patient information, have been mostly eliminated from medical brochures. ${ }^{1}$ On the second goal, training for health professionals, a nationwide programme to train medical school students in communicating with patients was proposed at the February workshop.

I welcome this open declaration of a fundamental shift towards informed patients (and physicians). In Muir Gray's words,

"People have a right to clean, clear drinking water as they have a right to clean, clear knowledge." ${ }^{10}$ Yet its execution will not be easy, mainly because it may be seen as a threat to financial interests in medicine and in industry. The National Cancer Plan will have to find ways to deal with these conflicts of interest. It is timely to do so. Otherwise, we risk the public losing even more trust in the healthcare system, including doctors.

Hopefully, Germany's paradigm shift will become a model for other countries where the goal is still to nudge as many citizens as possible into screening.

Competing interests: I have read and understood BMJ's policy on declaration of interests and have no relevant interests to declare.

Provenance and peer review: Commissioned; not externally peer reviewed.

Gigerenzer G. Breast cancer screening pamphlets mislead women. BMJ 2014;348:g2636. 2 NHS Cancer Screening Programmes. NHS breast screening programme: annual review 2011. www.cancerscreening.nhs.uk/breastscreen/publications/nhsbsp-annualreview2011. pdf.

3 Hoffmann TC, Del Mar C. Patients' expectations of the benefits and harms of treatments, screening, and tests: a systematic review. JAMA Int Med 2015;175:274-86.

4 Gigerenzer G, Mata J, Frank R. Public knowledge of benefits of breast and prostate cancer screening in Europe. J Natl Cancer Inst 2009;101:1216-20.

5 Helou A. Krebsfrüherkennung im Nationalen Krebsplan. Bundesgesundheitsblatt 2014:57:288-93.

6 Richter-Kuhlmann E. Nationaler Krebsplan-Perspectivenwechsel: Patient. Deutsches Ärzteblatt 2015;112:A-456.

7 Gigerenzer G, Gaissmaier W, Kurz-Milcke E, Schwartz LM, Woloshin SW. Helping doctors and patients make sense of health statistics. Psychol Sci Public Interest 2007;8:53-96.

8 Woloshin S, Schwartz LM. Communicating data about the benefits and harms of treatment: a randomized trial. Ann Int Med 2011:155:87-98.

9 Wegwarth O, Schwartz LM, Woloshin S, Gaissmaier W, Gigerenzer G. Do physicians understand cancer screening statistics? A national survey of primary care physicians. Ann Int Med 2012;156:340-9.

10 Better Value Healthcare. Our team. www.bvhc.co.uk/ourteam.html.

Cite this as: BMJ 2015;350:h2175

() BMJ Publishing Group Ltd 2015 